\title{
The road to entrepreneurial success: business plans, lean startup, or both?
}

\author{
Chris Welter \\ Miami University, Oxford, Ohio, USA, and \\ Alex Scrimpshire, Dawn Tolonen and Eseoghene Obrimah \\ Xavier University, Cincinnati, Ohio, USA
}

Received 3 August 2020

Revised 3 December 2020

Accepted 1 February 2021

\begin{abstract}
Purpose - The goal of this research is to investigate the relationship between two different sets of practices, lean startup and business planning, and their relation to entrepreneurial performance.

Design/methodology/approach - The authors collected data from 120 entrepreneurs across the US about a variety of new venture formation activities within the categories of lean startup or business planning. They use hierarchical regression to examine the relationship between these activities and new venture performance using both a subjective and objective measure of performance.

Findings - The results show that talking to customers, collecting preorders and pivoting based on customer feedback are lean startup activities correlated with performance; writing a business plan is the sole business planning activity correlated with performance.

Research limitations/implications - This research lays the foundation for understanding the components of both lean startup and business planning. Moreover, these results demonstrate that the separation of lean startup and business planning represents a false dichotomy.

Practical implications - These findings suggest that entrepreneurs should engage in some lean startup activities and still write a business plan.

Originality/value - This article offers the first quantitative, empirical comparison of lean startup activities and business planning. Furthermore, it provides support for the relationship between specific lean startup activities and firm performance.
\end{abstract}

Keywords Business planning, Entrepreneurship, Lean Startup

Paper type Research paper

\section{Introduction}

No business plan survives first contact with a customer - Steve Blank

This quote represents the differing perspectives on the value of business planning relative to the value of lean startup methods proposed by Blank and others (Blank and Dorf, 2012). Much of traditional entrepreneurial training centers on the business plan (Honig, 2004). Collective research on business planning's antecedents (Brinckmann et al., 2019) and its performance outcomes have found nuanced results (Brinckmann et al., 2010), but there seem to be at least some instances where business planning reliably increases performance (Welter and Kim, 2018). Studies suggest that the majority of prominent business schools offer business planning courses (Honig, 2004; Katz et al., 2016), and bookstores are filled with books

(C) Chris Welter, Alex Scrimpshire, Dawn Tolonen and Eseoghene Obrimah. Published in New England Journal of Entrepreneurship. Published by Emerald Publishing Limited. This article is published under the Creative Commons Attribution (CC BY 4.0) license. Anyone may reproduce, distribute, translate and create derivative works of this article (for both commercial and non-commercial purposes), subject to full attribution to the original publication and authors. The full terms of this license may be seen at http:// creativecommons.org/licences/by/4.0/legalcode

A portion of this research was funded by the Downing Scholars research grant at Xavier University.

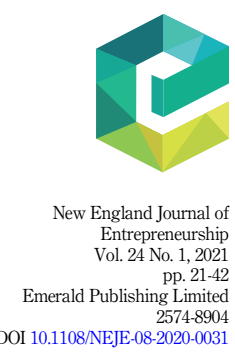


NEJE

24,1

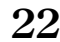

detailing how to write a business plan (Karlsson and Honig, 2007). Nonetheless, the research is fragmented at best, and often results in equivocal findings with regard to its relationship with firm performance (Brinckmann et al., 2010, Delmar and Shane, 2003; Gruber, 2007). This lack of clear indication from researchers opens the door for critique of business planning from proponents of the lean startup (Ghezzi et al., 2015).

Lean startup methods have drawn increasing attention in entrepreneurial communities (Ries, 2011). In accelerators, incubators and other spaces within startup ecosystems the wisdom of Eric Ries (2011) and Steve Blank (Blank and Dorf, 2012) can be heard in training sessions and everyday conversations. Some entrepreneurial programs have adopted lean startup methods as well (Bliemel, 2014). On one hand, conceptual articles have described how lean startup fits adjacent to current and past academic conversations (Contigiani and Levinthal, 2019). On the other hand, practitioner articles have discussed the benefits and limitations of the models (Ladd, 2016). In both cases, existing literature describes how these processes aim to avoid the pitfall of launching products that no one actually wants (Blank, 2013).

Despite all the popular attention given to lean startup methods, little empirical research has been completed (see Trimi and Berbegal-Mirabent (2012), Ghezzi et al. (2015), and Ghezzi (2019) for exceptions). Some researchers (e.g. Frederickson and Brem, 2017) have drawn the parallels between lean startup methods and effectuation (Sarasvathy, 2001), but these parallels do not sufficiently support the use of lean startup methods. While practitioners seem to embrace lean startup methods, academics have offered little in terms of direct investigation into those methods (Shepherd and Gruber, 2020). Most of the research on lean startup methods focuses on cognitive processes (Yang et al., 2018; York and Danes, 2014). Recent critique (Felin et al., 2019) coupled with the dearth of empirical research calls into question the efficacy of lean startup methods. To that end, more research is needed to see how lean startup methods relate to new venture success especially in comparison to business planning. This is particularly important as new venture formation activities are the practices that can legitimize the firm (De Clercq and Voronov, 2009).

As such, we propose the following question: which individual aspects of business planning and lean startup methods are related to success? We study the components of both business planning and lean startup methods as there is some academic support for aspects of lean startup such as experimentation (Carmuffo et al., 2019), but limited empirical investigation into lean startup more broadly. We specifically focus on the underlying activities that make up the processes of lean startup and business planning since our initial surveying showed that entrepreneurs often employ aspects of each. To examine this question, we created a survey that captured the various activities - both from lean startup and business planning - that entrepreneurs used in pursuing their new venture and compared those with measures of success.

Our findings suggest that certain lean startup activities and the act of writing a business plan are correlated with success. These findings help to undo a false dichotomy of either lean startup or business planning by suggesting that some activities from each side can lead to success. We contribute to business planning research by offering a possible explanation for the existing equivocal findings. Namely, that the act of writing a business plan may be important, but that the uses of a business plan for feedback or financing are not necessarily associated with success. We contribute to research on lean startup by offering the first quantitative support for specific lean startup activities. Taken together, this research lays the foundation for a more nuanced understanding of the value of business planning and lean startup methods.

\section{Theoretical framework and hypotheses}

\section{Business planning}

The literature on business planning is vast focusing on both antecedents to business planning (Brinckmann et al., 2019) and outcomes of it (Brinckmann et al., 2010). Honig and 
colleagues have driven much of the research into business planning since the turn of the century (Honig, 2004; Honig and Karlsson, 2004; Honig and Samuelsson, 2012, 2014; Karlsson and Honig, 2009). They have challenged prior planning-performance paradigms that suggested planning would naturally increase performance (Ajzen, 1985; Mintzberg and Waters, 1985; Ansoff, 1991). This debate about the value of planning has underscored the recent research into selection effects associated with business planning (Burke et al., 2010; Greene and Hopp, 2017).

Brinckmann et al. (2010) address this debate directly. Their meta-analytic review of business planning literature suggests that three contingencies need to be considered in terms of the effectiveness of business planning: uncertainty, limited prior information, and the lack of business planning structures. The presence of these three suggest that business planning may be less effective. We look at each of these three contingencies in more depth next.

For uncertainty, planning scholars (e.g. Priem et al., 1995) suggest that unstable and uncertain environments would benefit most from planning as planning can reduce uncertainty through facilitating faster decision-making (Dean and Sharfman, 1996). However, emergent strategies seem to be more effective at controlling uncertainty (Mintzberg, 1994; Sarasvathy, 2001). Brinckmann et al. (2010) confirms the latter intuition suggesting that uncertainty makes planning efforts less effective. This logic falls in line with research on effectuation (Sarasvathy, 2001), where planning is described as the appropriate strategy for risky environments and effectuation, in contrast, is appropriate for uncertain environments. Recent work has confirmed this logic depending on how accurate the entrepreneur can be when predicting the future (Welter and Kim, 2018).

Turning to the concept of limited prior information, planning proponents suggest that the shorter feedback cycles in new and small firms combined with the positive motivational effects of planning will make it more effective (Delmar and Shane, 2003). In essence, despite the lack of history for de novo firms, short cycle times create history quickly and planning itself serves to motivate these fledgling organizations. However, Brinckmann et al. (2010) find that these firms lack the information necessary to make such plans effective. As firms pursue novel strategies, planning seems to be less effective or firms abandon plans all together as they move forward (Karlsson and Honig, 2009).

Finally, for plans to be effective firms need to have the structures in place to both plan and make use of those plans (Brinckmann et al., 2010). New firms tend to lack the organizational structures relevant to create and use plans (Forbes, 2007). While Karlsson and Honig (2009) found that firms typically ignore or abandon plans after they have been made, often due to insufficient support structures, Honig and Samuelsson (2012) show that even when firms change their plans over time there is little impact on firm performance. In general, the literature on business planning suggests that planning has more benefits for established firms with data and history to support both the plan and the planning process.

The long history of the research in business strategy and other fields that support the relationship between planning and performance has arguably influenced the perception of business planning in entrepreneurship. Despite some research and growing popular sentiment that questions business planning, schools still teach it (Honig, 2004) and support organizations such as Small Business Development Centers (SBDC) and the Service Corps of Retired Executives (SCORE) encourage entrepreneurs to write business plans. While there may not be conclusive evidence that business planning will always increase performance, under certain conditions business planning does seem to be beneficial (Brinckmann et al., 2010). Thus, business planning for new ventures may or may not have a positive effect on success, but it is unlikely to have a negative one. Therefore, we hypothesize:

H1. Business planning activities improve the likelihood of success for new ventures. 
NEJE

24,1

Typically, business planning has been analyzed as the single act of writing a business plan (e.g. Honig and Karlsson, 2004). However, business planning is made up of a variety of activities (Gruber, 2007), which entrepreneurs may utilize as a whole, or simply choose parts of the business planning process. It is worth noting that these specific activities are not mutually exclusive with lean startup activities that we will detail later. One source of the gap between the prevalence of business planning use and research supporting the efficacy of business plans may be this holistic perspective. The constituent parts of business planning may be executed as a whole, or may be chosen a la carte. Examining the various activities that make up business planning offers insight into which aspects of the process are related to firm performance.

Arguably the first step in the business planning process is the work that precedes the actual writing of a business plan. First, entrepreneurs must collect data - typically external data (Brinckmann et al., 2010). This data collection process may or may not result in an actual business plan being written and, therefore, can be treated as a separate step itself.

Beyond the data collection and writing, the planning process can play a role in routinizing the initial practices of entrepreneurs. While entrepreneurs may engage in social resourcing (Keating et al., 2014) and collective sense-making (Wood and McKinley, 2010), the act of codifying the results of these activities can objectify these practices. Entrepreneurs engage socially on a number of dimensions in the pursuit of a venture, but physically writing down a business plan that can be shared externally can serve as a commitment mechanism. Entrepreneurs may share this plan with external stakeholders simply for feedback (Wood and McKinley, 2010) or they may use it to seek funding (Richbell et al., 2006).

Any entrepreneur may complete some combination of these four activities. Thus, a more nuanced approach to understanding the relationship between business planning and firm performance should examine the activities individually [1]. As such, we hypothesize:

H1a. Writing a business plan improves the likelihood of success for new ventures.

H1b. Gathering secondary data improves the likelihood of success for new ventures.

H1c. Sharing a business plan with potential stakeholders in order to get feedback improves the likelihood of success for new ventures.

H1d. Sharing a business plan with potential financiers in order to obtain funding improves the likelihood of success for new ventures.

\section{Lean startup}

The concept and the phrase "Lean Startup" stem from Eric Ries (2011) and his popular press book by the same name. The phrase borrows from the idea of lean manufacturing in the sense of eliminating waste and pushing production and supply as late in the process as possible to delay purchasing until the last moment. The book draws primarily on Ries's personal experience in founding a company along with some consulting work. Further development of the ideas around lean startup methods comes from Steve Blank (Blank and Dorf, 2012). Blank (2013) described three principles of lean startup: hypothesis creation, customer development, and agile development. Hypothesis creation represents the belief that founders begin with little more than untested hypotheses. Customer development represents the approach of interviewing and interacting with customers in order to verify or discard the aforementioned hypotheses. Finally, agile development conceptualizes that minimally viable products (MVPs) are deployed quickly to verify the hypotheses that are believed to be true.

These concepts are often practiced by entrepreneurs and taught at incubators and accelerators (Ladd, 2016), but there is little academic research to support these practices. Ghezzi et al. (2015) offer one of the only comparative empirical studies between lean startup and business planning. Their findings from a four-case study suggest that lean startup 
methods lead to superior outcomes. The majority of other papers are conceptual explorations of lean startup methods focusing on the decision-making of entrepreneurs (Frederickson and Brem, 2017; Yang et al., 2018; York and Danes, 2014). These conceptual pieces draw parallels between lean startup and effectuation (Sarasvathy, 2001).

The literature on effectuation is much larger than that of lean startup (see recent reviews and retrospectives by Arend et al. (2015) and Reymen et al. (2015)). Effectuation has been defined as entrepreneurial expertise that utilizes heuristics to make decisions focused on the means available rather than on desired ends (Sarasvathy, 2001). One heuristic, in particular, has driven the comparison between lean startup and effectuation: experimentation (Camuffo et al., 2019). However, the comparisons may stem from the lack of clear boundaries in effectuation (see Welter et al., 2016). While some researchers might argue that effectuation is a more robust articulation of lean startup (Frederickson and Brem, 2017), there are significant departures. Effectuation makes no mention of MVPs or agile development, but instead focuses on the means at hand (Sarasvathy and Dew, 2008). These means direct the venture as opposed to a focus on a specific end in mind (Sarasvathy, 2001). This is in contrast to lean startup methods that create specific tests in order to verify a predetermined path (Blank, 2013). Thus, researchers have suggested that lean startup intersects with effectuation, as well as other research streams (Contigiani and Levinthal, 2019; Ghezzi, 2019).

Taken together, there is some theoretical support for lean startup combined with a wealth of popular interest and support. Lean startup has received recent criticism for its ability to generate hypotheses and experiments that lead to truly novel solutions (Felin et al., 2019). Nonetheless, this critique currently lacks empirical support, underscoring the need for empirical study. To our knowledge, there has only been one quantitative empirical study of lean startup (Ghezzi, 2019), which examined utilization and approach rather than addressing the relationship between lean startup and success. Given the widespread use and connections to theory we hypothesize:

H2. Utilizing lean startup methods improves the likelihood of success for new business ventures.

Similar to business planning, lean startup is a process with several component parts from which an entrepreneur may select without needing to accomplish each task. Moreover, these component parts may be used in conjunction with business planning activities. Since lean startup has been developed more by practitioners than academics, there is not a clearlydefined, comprehensive list of activities that constitutes lean startup. Bortolini et al. (2018) review the academic and popular press literature on lean startup and describe the process at a more theoretical level than the work of Blank (2013) and Ries (2011). Between these two perspectives, a specific list of six lean startup activities can be derived.

The lean startup process begins with customer discovery (Blank and Dorf, 2012). In its most basic sense, the process of customer discovery begins with interviewing potential customers to surface their problems. Blank (2013) describes how lean startups "get out of the building" throughout the process to validate customer assumptions regarding all aspects of a potential business model. This validation process involves a variety of different forms of potential customer interviews.

From there, entrepreneurs craft hypotheses and build experiments as Bortolini et al. (2018) describe. This part of the process can be deconstructed into developing prototypes, showing those prototypes to customers, and running experiments. These sub-processes are discrete steps that may depend on each other, but may also occur independently. For instance, entrepreneurs may develop prototypes in their own quest to improve the product without actually showing a given prototype to potential customers. Alternatively, entrepreneurs may run experiments that do not necessarily involve the use of a prototype. These experiments may include observing customers in their daily routine to better understand customer 
NEJE

24,1

\section{6}

problems. Each of these processes, however, align with the practitioner perspectives and the theoretical perspectives (Blank and Dorf, 2012; Bortolini et al., 2018).

Beyond these specific activities, we examine two other activities within lean startup: collecting preorders and pivoting. Collecting preorders for new products has been suggested by Ries (2011), but also aligns with research on enrolling external stakeholders (Burns et al., 2016) and the principles of effectuation (Sarasvathy, 2001). By seeking out early stakeholders to make commitments like preorders or input on prototypes, entrepreneurs seek social resources to enable and direct their progress (Keating et al., 2014).

The final activity we address is pivoting, which involves altering the course of the firm, typically based on user feedback. Pivoting plays a central role in lean startup (Bortolini et al., 2018) and has recently garnered attention in entrepreneurship research more broadly (Wood et al., 2018). Changing course represents the logical step following the proverbial "fail fast, fail cheap" mantra of entrepreneurs. It may follow from earlier activities, such as customer interviews or experimentation, but it need not [2]. Based on the above, we hypothesize:

H2a. Interviewing potential customers improves the likelihood of success for new business ventures.

H2b. Developing a prototype improves the likelihood of success for new business ventures.

H2c. Showing a prototype to potential customers improves the likelihood of success for new business ventures.

H2d. Experimenting to test business model assumptions improves the likelihood of success for new business ventures.

H2e. Collecting preorders improves the likelihood of success for new business ventures.

$H 2 f$. Pivoting based on customer feedback improves the likelihood of success for new business ventures.

\section{Method}

Survey

We began our study by conducting semi-structured interviews with five entrepreneurs to guide the construction of the survey. These entrepreneurs were selected from the authors' personal networks to represent a variety of perspectives and experiences. The group included two female founders and three male founders; two of the founders created high-tech scalable businesses and three represented small businesses. The interviews lasted $75 \mathrm{~min}$ on average.

All interviewees were familiar with business plans. All interviewees had heard of "lean startup" but only one entrepreneur had any education on the subject - they had read Eric Ries's book (Ries, 2011). Nonetheless, none of the entrepreneurs could articulate specific aspects of lean startup or how it would be different from or related to writing a business plan.

The data collected from these interviews was used to develop a survey for distribution to a wider group of entrepreneurs. Within the qualitative data we noted how both business planning and lean startup represented groups of activities to the entrepreneurs. In discussing business planning, all of the entrepreneurs discussed more than simply producing a formal business plan. While four of the five entrepreneurs created formal business plans, each discussed a slightly different process. Some included financial planning while others mentioned secondary research. On the lean startup approach, the entrepreneurs did not specifically state which activities they pursued that were in line with lean startup, but multiple entrepreneurs mentioned each of the aspects of lean startup that we included in the survey. 
This qualitative investigation altered our survey design to focus more on the activities that entrepreneurs completed rather than focusing on their understanding of the different approaches. Before distributing the survey, we tested it with two entrepreneurs to obtain feedback on its understandability - one from the original interviewees and one unfamiliar with the research project. Based on these tests, minor modifications to word choice were made.

We reached out to the startup ecosystem in a major Midwestern city. The online survey was emailed to incubators, accelerators, individual entrepreneurs, and organizations that reach outside the Midwest. Participation in the study was voluntary. Participants received a $\$ 1$ USD donation to a non-profit organization of their choice for completing the survey. A total of 41 entrepreneurs responded to the initial survey request. We excluded seven of these cases because they did not adequately describe their business.

To bolster the sample size, we enlisted the Qualtrics panel development team to collect approximately 100 additional survey responses from entrepreneurs. Qualtrics, in addition to providing online survey tools, is a research panel aggregator with the ability to recruit hardto-reach demographics. Qualtrics utilizes specialized recruitment campaigns to assemble niche survey panels based on pre-specified criteria. To fit in this group, entrepreneurs must own a business that they have started within the last ten years. Respondents in this group were compensated with $\$ 25$ USD for their participation and were not offered any donation option. A total of 106 completed surveys were returned from this group. We excluded 20 of these cases because they were unable to adequately describe their business. See the Appendix for the complete survey instrument.

\section{Participants and procedures}

The participants completed an online questionnaire with thirty-two questions on the details of how they started their business, the success of the business, activities they conducted while starting the business, and demographic variables. The sample was recruited via a snowball sample method as well as through a Qualtrics panel as described above.

The majority of our sample is comprised of Caucasians $(81.7 \%)$, followed by Black/ African Americans (11.7\%), then Hispanics (3.3\%), then Asians (1.7\%). The median age of our sample was 46.5 years old and the sample was $49.2 \%$ female. The majority of our dataset is currently married $(61.7 \%)$ with $55.8 \%$ having at least a bachelor's degree. Table 1 shows the means and standard deviations for each of the variables as well as the correlations between them.

\footnotetext{
Measures

Dependent variables. There are various difficulties in obtaining concrete objective measures of success from entrepreneurs. Reasons stem from factors such as small business owners not always running their businesses to maximize financial performance (Jacobs et al., 2016) or running a business because it allows for a preferred lifestyle (Jennings and Beaver, 1997; Walker and Brown, 2004). Because of this, there are a few ways researchers can gain acceptable insight into the success of an entrepreneurial venture. One approach is to use subjective measures when other types of information are unavailable (Dawes, 1999). Thus, following previous research (Besser, 1999; Jacobs et al., 2016) which has noted that entrepreneurial success may not always mean optimal financial measures and instead may be more along the lines of maintaining an acceptable level of income for themselves and their employees (Beaver, 2002) or sustaining a lifestyle more aimed at being part of a creative output than being financially successful (Chaston, 2008), we first analyzed the entrepreneurs' perceived organizational success. A second approach is to ask about objective success measures. We strengthened our study by asking entrepreneurs about objective measures of
} 
NEJE
24,1

\section{8}

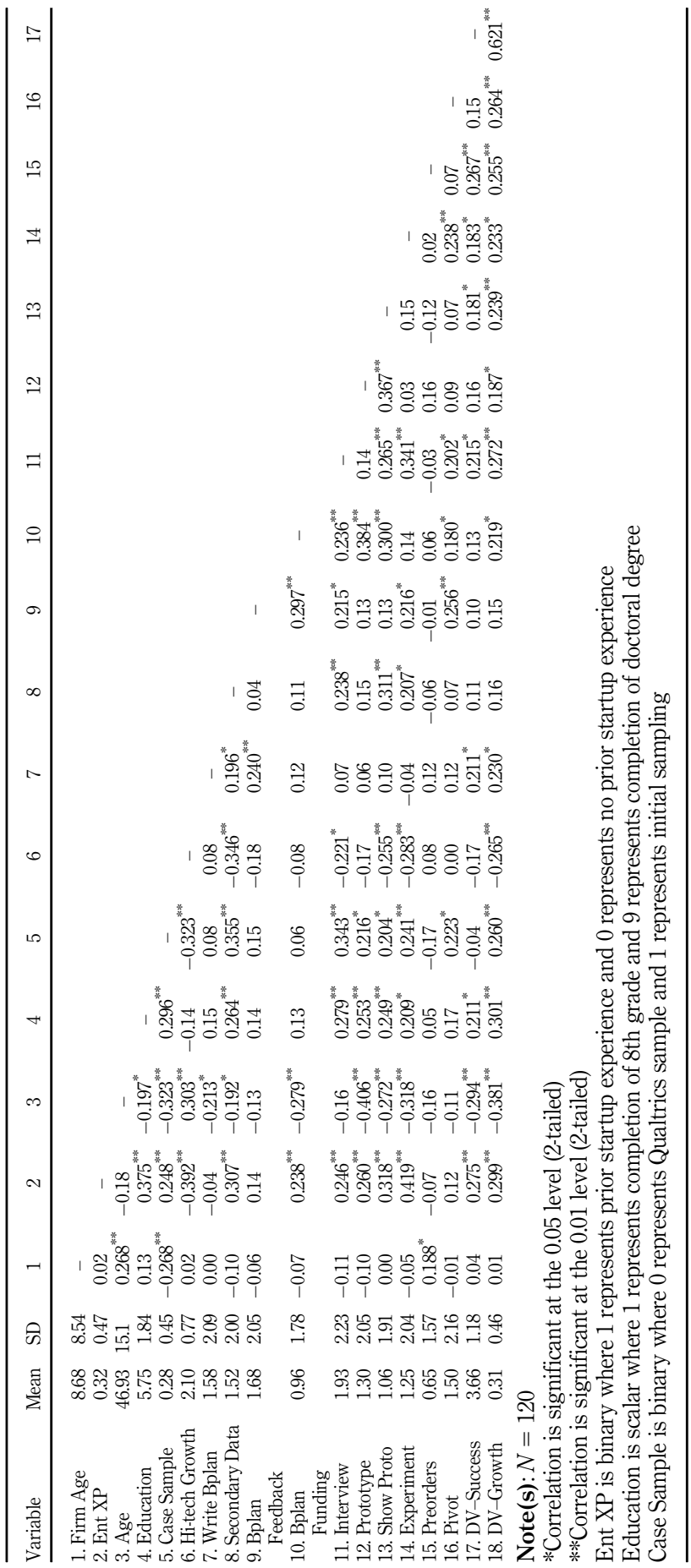

Table 1.

Correlations 
their firm's success via focusing on their firm's growth, specifically, asking about objective growth indicators in terms of increased number of employees, increased number of customers, or increased revenue as previous research has used these measures to indicate success (Walker and Brown, 2004). Therefore, we analyzed the full model for both the subjective and objective dependent variables.

Success. Given that entrepreneurial motivations can vary widely (Shane et al., 2003), defining success can vary based on the individual. To address this, studies have surveyed entrepreneurs for their subjective perception of their venture's success (Fisher et al., 2014; Keith et al., 2016). Walker and Brown (2004, p. 585) find that "Personal satisfaction, pride and a flexible lifestyle were the most important considerations for these business owners." They argue that objective, financial measures that are often used in research offer objectivity and accessibility, but may not capture the true value of success for many entrepreneurs. These alternative motivations make success difficult to quantify objectively, leading researchers to utilize more subjective measures. Therefore, in line with prior research on entrepreneurial success perceptions (Jacobs et al., 2016; Besser, 1999), we asked respondents "How strongly do you agree or disagree with the following statement? My business is a success." Respondents rated their agreement on a five-point Likert scale $(1=$ Strongly Agree, 5 = Strongly Disagree).

Firm Growth:. To strengthen the findings from our subjective measure of success we also asked respondents about objective measures of firm growth. By asking respondents about obvious measures of growth we can offer a more objective view on the success of the firm. We asked respondents if their firm had grown by any of the following three metrics: number of employees, number of customers, or total revenue (cf. Jacobs et al., 2016). Given the variety of motivations of entrepreneurs, we chose not to limit the type of growth that would reflect success. In some cases, an entrepreneur may seek to increase the impact of the business by providing services to a greater number of customers, while maintaining a lean staff to control pricing. Alternatively, an entrepreneur may be seeking autonomy, and therefore choose not to hire in order to create greater autonomy. However, it is likely that some firm growth - in revenue, employees, or customers - is likely to occur in successful firms. Therefore, we combined these three types of growth as a dichotomous variable, wherein growth in any one or more of these areas would be coded as a " 1 " for growth and an answer of no growth in all of these areas would be coded as a "0" for no growth.

Independent variables. Business Planning. We defined business planning using four activities. We asked respondents if they (1) wrote a business plan [Write BPlan]; (2) gathered secondary data on industry statistics or trends [Secondary Data]; (3) shared your business plan with people outside the company for feedback [BPlan Feedback]; and (4) shared your business plan with people outside the company for funding [BPlan Funding]. These were not loaded as a factor as these do not represent an underlying factor, but rather are individual activities that all represent a variety of activities pertaining to the use of business plans.

Lean Startup. We defined lean startup using six activities. We asked respondents if they (1) interviewed potential customers [Interview]; (2) created a prototype [Prototype]; (3) showed a prototype to potential customers for feedback [Show Proto]; (4) conducted an experiment to better understand some portion of your business [Experiment]; (5) used customer feedback to alter the direction of your business ("pivoted") [Pivot]; and (6) accepted money for preorders [Preorders]. Similar to business planning activities, these were not loaded as a factor, as these activities do not represent an underlying factor, but rather a collection of potential activities.

For each of the IVs, respondents were first asked which of the above activities they engaged in during their venture startup process. The order of the activities was randomized. For each activity that was selected, respondents were asked to rate "how much did each of those activities positively impact the performance of this venture?" Respondents were given a five-point Likert scale ( $1=$ "Not at all" to $5=$ "A great deal") and if the respondent did not do 
NEJE

24,1

the activity, the response was coded as a 0 . To calculate the IVs, each response was weighted by the level of impact. For example, if the respondent rated Experiment as a 5 for a great deal of impact, then it would be coded 5 . If it was rated 3 , then it would be coded 3 . Any activity not completed was not rated (or effectively coded a 0 ).

We used the ratings to allow for variance in the impact of any activity. In our preliminary interviews, we heard that entrepreneurs may have performed the same activity, such as interviewing customers, but some placed a greater emphasis on this activity whereas others performed it only cursorily. We also performed a robustness check on the data using nonweighted values for the IVs and found similar results (these are available from the corresponding author upon request).

Control variables. We controlled for the following variables: (1) the firm's age in years [Firm Age]; (2) the entrepreneur's prior startup experience [Ent XP]; (3) the entrepreneur's age in years [Age]; (4) the entrepreneur's education level [Education]; (5) the case sample [case Sample]; and (6) if the firm was a high-tech growth firm [Hi-tech growth firms]. Firm age is likely related to perceptions of success in the minds of entrepreneurs. If an entrepreneur perceives themselves as unsuccessful, they are likely to quit pursuing their venture. Thus, entrepreneurs with older businesses are more likely to have higher perceptions of their own success. Ent XP, Age, and Education have all been investigated in the past for their relationship to entrepreneurial firm performance (e.g. Hechavarría and Welter, 2015). We also control for the case sample since our sample was collected in two different processes. Finally, we control for Hi-tech growth firms since some firms in our sample are oriented toward accelerated growth and others may be content with stable returns, which may impact the use and effectiveness of business planning (Brinckmann et al., 2010).

\section{Results}

Regression results for success $D V$

We tested our hypotheses using hierarchical regression [3]. In Step 1, we entered Firm Age (in years), the entrepreneur's prior startup experience, the entrepreneur's age, the entrepreneur's education level, the case source, and whether the firm was a hi-tech growth firm as controls (Van Dyne and LePine, 1998). In Step 2, we entered our independent variables that relate to the business plan approach: writing a business plan, gathering secondary data on the industry, sharing the business plan to receive feedback, and sharing the business plan to obtain funding. We also included the variables related to the lean startup approach: interviewing potential customers, creating prototypes, showing prototypes to potential customers for feedback, conducting an experiment to better understand a portion of the business, pivoting based on customer feedback, and accepting money for preorders.

Table 1 reports descriptive statistics and correlations, whereas Table 2 presents the hierarchical regression results for the success dependent variable. As can be seen in Table 2 , consistent with H1a, writing a business plan was related to success $(\beta=0.09, p=0.09)$. However, we do not find support for our other hypotheses: gathering secondary data on the industry, sharing the business plan to receive feedback, and sharing the business plan to obtain funding were all not significantly related to success.

When we looked at the activities that contribute to lean startup methods, we found that interviewing potential customers $(\beta=0.09, p=0.08)$ and accepting money for preorders $(\beta=0.15, p=0.03)$ supported H2a and H2e respectively, suggesting these are correlated with success. Similar to the business plan approach there was not sufficient support for all our hypotheses: creating prototypes, showing prototypes to potential customers for feedback, conducting an experiment to better understand a portion of the business, and pivoting were not supported. The findings with regard to each hypothesis are summarized in Table 3. 


\begin{tabular}{|c|c|c|c|}
\hline Variable & $\begin{array}{l}\text { Step } 1 \\
B\end{array}$ & $\begin{array}{l}\text { Step } 2 \\
B\end{array}$ & $\begin{array}{r}\text { Business plans } \\
\text { and lean }\end{array}$ \\
\hline Constant & \multirow{19}{*}{$\begin{array}{c}4.43^{* *} \\
0.005 \\
0.52^{*} \\
-0.02^{* *} \\
0.08 \\
-0.61^{*} \\
-0.10\end{array}$} & $4.18^{* *}$ & startup \\
\hline Firm Age & & -0.002 & \\
\hline Ent XP & & $0.59 *$ & \\
\hline Age & & $-0.02+$ & \\
\hline Education & & 0.04 & 31 \\
\hline Case sample & & $-0.69 *$ & \\
\hline High Tech Firm & & -0.16 & \\
\hline Business Plan & & $0.09+$ & \\
\hline Write business plan & & & \\
\hline Secondary data & & -0.02 & \\
\hline Business plan feedback & & -0.02 & \\
\hline Business plan funding & & -0.05 & \\
\hline Lean Startup & & $0.09+$ & \\
\hline Interview & & & \\
\hline Prototype & & -0.02 & \\
\hline Show prototype & & 0.04 & \\
\hline Experiment & & -0.02 & \\
\hline Preorders & & $0.15^{*}$ & \\
\hline Pivot & & 0.06 & \\
\hline$R^{2}$ & 0.19 & 0.30 & \\
\hline Adjusted $R^{2}$ & 0.15 & 0.19 & \\
\hline$R^{2}$ change & 0.19 & 0.10 & $\begin{array}{l}\text { Table } 2 . \\
\text { Summary regression }\end{array}$ \\
\hline $\begin{array}{l}\operatorname{Note}(\mathbf{s}): N=120 \\
{ }^{+} p<0.10 ; * p<0.05, * * p \leq 0.01\end{array}$ & & & $\begin{array}{l}\text { results for the } \\
\text { success DV }\end{array}$ \\
\hline
\end{tabular}

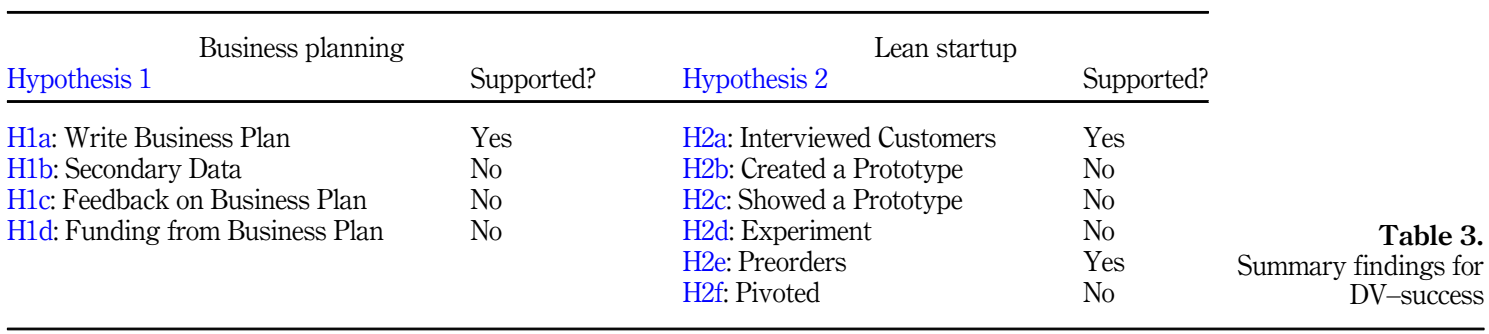

\section{Regression results for growth $D V$}

Similar to the subjective success dependent variable, we tested our hypotheses using logistic regression for our objective growth dependent variable [4]. A logistic regression was performed for each of our approaches, the business plan and lean startup since our growth DV is dichotomous (Mason et al., 2018).

Table 1 reports descriptive statistics and correlations, whereas Table 4 presents the logistic regression results for the effects of writing a business plan, gathering secondary data on the industry, sharing the business plan to receive feedback, and sharing the business plan to obtain funding had on our growth dependent variable. The logistic regression model was statistically significant, $\chi^{2}(10)=39.16, p<0.005$. The model explained 39.2\% (Nagelkerke $R^{2}$ ) of the variance in business growth and correctly classified $69.2 \%$ of cases. As can be seen in Table 4 , consistent with H1a, writing a business plan was related to success $(\beta=0.30$, $p=0.036$ ). As before we did not find support for our other hypotheses: gathering secondary 
NEJE

24,1

\begin{tabular}{lcc}
\hline & Business plan & Lean startup \\
Variable & $B$ & $B$ \\
\hline Constant & 2.18 & 2.10 \\
Firm Age & 0.03 & -0.01 \\
Ent XP & 1.13 & 1.24 \\
Age & $-0.04^{* *}$ & $-0.05^{*}$ \\
Education & 0.18 & 0.16 \\
Case sample & 0.65 & 0.25 \\
High Tech Firm & -0.61 & -0.48 \\
Business Plan & $0.30^{*}$ & \\
Write business plan & & \\
Secondary data & -0.17 & \\
Business plan feedback & 0.01 & $0.25^{+}$ \\
Business plan funding & 0.19 & \\
Lean Startup & & -0.11 \\
Interview & & 0.14 \\
Prototype & & -0.09 \\
Show prototype & & $0.89^{*}$ \\
Experiment & & $0.34^{*}$ \\
Preorders & & $0.51^{*}$ \\
Pivot & & \\
$R^{2}$ & & \\
Note(s): $N=120$ & $0.39^{*}$ & \\
${ }^{+} p<0.10 ; * 00.05, * * p \leq 0.01$ & & \\
\end{tabular}

Table 4.

Summary regression results for the growth DV

data on the industry, sharing the business plan to receive feedback, and sharing the business plan to obtain funding.

Next, we looked at the actions that constitute lean startup, interviewing potential customers, creating prototypes, showing prototypes to potential customers for feedback, conducting an experiment to better understand a portion of the business, and pivoting based on customer feedback had on our growth dependent variable. The logistic regression model was statistically significant, $\chi^{2}(12)=53.82, p<0.005$. The model explained $51.0 \%$ (Nagelkerke $R^{2}$ ) of the variance in business growth and correctly classified $85 \%$ of cases. Our logistic regression results found that interviewing potential customers $(\beta=0.25, p=0.08)$, accepting money for preorders $(\beta=0.89, p=0.04)$, and pivoting based on customer feedback $(\beta=0.34, p=0.03)$, provided support for $\mathrm{H} 2 \mathrm{a}, \mathrm{H} 2 \mathrm{e}$, and $\mathrm{H} 2 \mathrm{f}$ respectively, suggesting these are correlated with success in terms of growth. We did not find support for our other hypotheses about lean startup activities. These were, creating prototypes, showing prototypes to potential customers for feedback, conducting an experiment to better understand a portion of the business, and pivoting. The findings with regard to each hypothesis are summarized in Table 5.

Table 5.

Summary findings for DV-growth

\begin{tabular}{llll}
\hline $\begin{array}{l}\text { Business planning } \\
\text { Hypothesis 1 }\end{array}$ & Supported? & Lean startup & Hypothesis 2 \\
\hline H1a: Write Business Plan & Yes & H2a: Interviewed Customers & Yes \\
H1b: Secondary Data & No & H2b: Created a Prototype & No \\
H1c: Feedback on Business Plan & No & H2c: Showed a Prototype & No \\
H1d: Funding from Business Plan & No & H2d: Experiment & No \\
& & H2e: Preorders & Yes \\
& & H2f: Pivoted & Yes \\
\hline
\end{tabular}




\section{Discussion}

In this paper, we sought to understand the relationship between lean startup activities and success as well as the relationship between business planning activities and success. To answer this question, we began by gathering qualitative data from entrepreneurs to better understand their perspective and language regarding these two approaches. From there, we created a survey and collected responses from 120 entrepreneurs about their activities and their perception of success and the growth of their firms. Controlling for common influencers of success, we found that the act of writing a business plan (H1a), interviewing potential customers (H2a), and taking preorders (H2e) were all correlated with subjective perceptions of success. For the firm growth dependent variable, we found that the act of writing a business plan (H1a), taking preorders (H2e), and pivoting based on customer feedback (H2f) were all correlated with objective measures of firm growth. Interestingly, these results represent a combination of lean startup and business planning activities. What is more, the two activities that are supported by both dependent variables, represent the most well-researched activities. As mentioned, the literature on business planning is well developed (Honig and Karlsson, 2004), and the use of preorders is most directly tied to research on enrolling stakeholders (Burns et al., 2016) as well as effectuation (Sarasvathy, 2001).

Our results give some understanding to the prior equivocal findings on business planning (Brinkmann et al., 2010). The qualitative data we gathered suggests that entrepreneurs complete different activities in their business planning process. In the past, there has not been much discussion about separate aspects of business planning or the impact they may have. Our findings suggest that the act of writing a business plan is related to success, but the other business planning activities - gathering secondary data, sharing the business plan for feedback or funding - are not related. This suggests that the planning process itself may mean more than the uses of a business plan. Even if a business plan is not revised or revisited as an entrepreneur pursues their venture (Karlsson and Honig, 2009), the act of writing the plan is still connected with success. Entrepreneurs going through the exercise of planning are likely to gain a better understanding of the entire endeavor of launching a new business. This would give entrepreneurs a better grasp of what the range of possible outcomes would be and likely temper any overly optimistic and unfounded hopes. Therefore, it is likely that simply writing the business plan helps calibrate entrepreneur expectations, which, in turn, helps entrepreneurs achieve success.

Rather than viewing lean startup as a cohesive whole, our qualitative data suggests that entrepreneurs make use of differing combinations of lean startup activities. This discovery informed our survey which offers some of the first direct quantitative evidence of the efficacy of lean startup methods. What we find, however, is that not all activities are linked to success. Perhaps the most straightforward finding is that taking preorders is correlated with both subjective and objective measures of success. If entrepreneurs are able to complete their first sales prior to actually creating their products or services, then success seems much more likely. Venture success, in this case, is agnostic toward the level of innovation in the firm. As such, the critique of lean startup from Felin et al. (2019) as a method that helps orient entrepreneurs to ideas that can be quickly and transparently tested still requires further investigation.

The other relevant activities are those most aligned with customers. Interviewing customers ensures that entrepreneurs design businesses that serve customers rather than building something that no one wants (Blank and Dorf, 2012). However, it is worth noting that interviewing customers must be done with an awareness of the entrepreneur's own cognitive biases (Chen et al., 2015). Furthermore, pivoting as a result of these discussions with customers also shows a response to customers' desires.

The most interesting aspect of our findings is likely the combination of activities across business planning and lean startup. While lean startup proponents might argue that "no
Business plans and lean startup 
NEJE

24,1

business plan survives its first contact with customers" (Blank and Dorf, 2012, p. 53), the act of writing a business plan is correlated with success. It is worth noting that the separation between lean startup and business planning may be a false dichotomy. The underlying activities are not mutually exclusive and do not seem to be detrimental to each other. It is entirely possible, and based on these results advisable, that an entrepreneur would interview customers throughout the process of creating a business plan and use customer feedback to alter both the plan and the business itself. Furthermore, taking customer preorders serves to solidify the relationship between customers and the firm which would only improve that communication.

\section{Limitations}

In order to create one of the first quantitative, empirical investigations of business planning and lean startup practices, some tradeoffs needed to be made. We believe that while these limitations may restrict the strength of some of our findings, the direct nature of our approach offers a contribution to the ongoing conversations among scholars and practitioners.

Our sample size is 120 . Obviously, a larger sample may lead to more robust and generalizable results. Furthermore, we gathered the sample using two different methods and controlling for the sample method was a significant predictor. We leave it to further research to expand upon our findings and investigate various entrepreneurial samples for differences that may arise.

One of our dependent variables was a subjective measure of success, which may be considered a weakness. We used this measure given the variety of preferred outcomes an entrepreneur may be pursuing - financial objectives, personal objectives, or mission-based objectives. Our other dependent variable was an objective measure of growth across three categories and serves to bolster confidence in the subjective measure.

Another area of concern may be common method variance given that we collected both independent variables and dependent variables from the same instrument. To address this concern, we collected data from individual entrepreneurs that all represented different companies and utilized two different samples so as to minimize the issues that may arise from common method variance (Chang et al., 2010). Lastly, our independent variables are more objective. For example, writing a business plan is a discrete event as is creating a prototype. For these reasons, we do not believe the common method variance is a major concern for this study.

One other potential weakness is the degree to which entrepreneurs actually utilized the activities of lean startup or business planning. The weighting scheme we employed aims to address this issue by weighting the degree to which entrepreneurs found each activity useful. However, we cannot be sure whether or not an entrepreneur executed the given activity well and this variability goes uncaptured in our study. Quantitative studies like this one will typically suffer from this limitation but case studies may be able to overcome these weaknesses (see Ghezzi et al., 2015).

Finally, our design is cross sectional and does not allow us to make causal inferences. We can only imply the relationship between our independent and dependent variables. Our hope is this is a first step to future research which may be better able to test the causality of the various aspects of business planning and lean startup as they relate to entrepreneurial success.

\section{Implications for research and practice}

This manuscript has important implications for research and practice. With respect to research, we have demonstrated that aspects of business planning and lean startup both are associated with success. Furthermore, entrepreneurs seem unlikely to enact either business planning or lean startup wholesale but are likely to pursue individual aspects of these 
concepts. Future research can investigate how entrepreneurs select between activities as well as how training and education regarding these practices impact the entrepreneurs' choice. The training and education surrounding the entrepreneur represent aspects of the organizing context (Johannisson, 2011), which influence how entrepreneurs construct their firms. Therefore, future research could add further institutional aspects or conduct randomized controlled trials to see the impact of these practices in the organizing context.

In terms of implications for practice, this research highlights the use of a variety of activities when it comes to entrepreneurial success. Some of the activities from both lean startup and business planning are useful for entrepreneurs. This also offers insight for educators as they seek to equip the next generation of entrepreneurs. Educators can offer potential entrepreneurs a wide range of activities without prognosticating one aspect of the false dichotomy between lean startup and business planning.

\section{Conclusion}

In this paper, we provide one of the first quantitative empirical studies investigating lean startup methods and business planning. In breaking down these areas, we undermine the false dichotomy between these two startup tools. Our findings demonstrate that truly understanding customers through preorders and interviews can lead to better business plans and better pivots. Ultimately, this results in firms with a greater chance of success. Understanding the variety of activities that entrepreneurs can pursue helps entrepreneurs and educators increase the chances of success for new businesses.

\section{Notes}

1. We do not believe that business planning exists as a latent construct necessarily comprised of these activities, but rather each of these activities are potential components of the concept referred to as "business planning" in prior research.

2. Similar to business planning activities, we believe that lean startup is not a latent construct but rather these activities in some combination is what is meant when practitioners and scholars refer to lean startup. As such we test each of the activities individually rather than as a construct.

3. Following the extant guidelines on regression assumptions (Osborne and Waters, 2002), we tested our model to ensure the regression assumptions were met. First, to check if our error terms (Flatt and Jacobs, 2019) are normally distributed, the $P$-P plot suggests normality as the plot is largely linear. Second, to check for a linear relationship between the independent and dependent variable, our residual plot showed a linear relationship. Third, as our variables were not latent, there is no concern for measurement error for this approach. However, we did follow best practices suggested by Flatt and Jacobs (2019) and tested the Durbin-Watson statistic. Our value for this measure is 1.5 and their guidelines are that this statistic should be close to 2 . Values between 1.2 and 1.6 represent only a minor violation of the statistical independence of error terms. Finally, to address the assumption of homoscedasticity, inspection of our standardized residuals showed our residuals scattered around the 0 (horizontal line). Therefore, for our dependent variable of success, we can feel comfortable our data meets the assumptions of linear regression.

4. As this dependent variable was analyzed using logistic regression, we analyzed our data following best practices from Garson (2012). First, our dependent variable is dichotomous. Second our scatterplot showed no outliers in our data. Third, the correlation table showed no evidence for multicollinearity as no correlations were above 0.9 (Tabachnick et al., 2007). Hence, we feel our data meets the assumptions for logistic regression.

\section{References}

Ajzen, I. (1985), "From intentions to actions: a theory of planned behavior", Action Control, Springer, Berlin, Heidelberg, pp. 11-39. 
NEJE

24,1

\section{6}

Ansoff, H.I. (1991), "Critique of Henry Mintzberg's 'The design school: reconsidering the basic premises of strategic management”, Strategic Management Journal, Vol. 12 No. 6, pp. 449-461.

Arend, R., Sarooghi, H. and Burkemper, A. (2015), "Effectuation as ineffectual? Applying the 3E theory-assessment framework to a proposed new theory of entrepreneurship", Academy of Management, Vol. 40 No. 4, pp. 630-651.

Beaver, G. (2002), Small Business, Entrepreneurship and Enterprise Development, Pearson Education, Harlow.

Besser, T.L. (1999), "Community involvement and the perception of success among small business operators in small towns", Journal of Small Business Management, Vol. 37 No. 4, pp. 16-29.

Blank, S. (2013), "Why the lean start-up changes everything", Harvard Business Review, Vol. 91 No. 5, pp. $64-72$.

Blank, S. and Dorf, B. (2012), “The startup owner's manual”, The Step-by-step Guide for Building a Great Company, Vol. 1.

Bliemel, M. (2014), "Getting entrepreneurship education out of the classroom and into students' heads", Entrepreneurship Research Journal, Vol. 4 No. 2, pp. 237-260.

Bortolini, R.F., Nogueira Cortimiglia, M., Danilevicz, A.D.M.F. and Ghezzi, A. (2018), "Lean startup: a comprehensive historical review”, Management Decision. doi: 10.1108/MD-07-2017-0663.

Brinckmann, J., Grichnik, D. and Kapsa, D. (2010), "Should entrepreneurs plan or just storm the castle? A meta-analysis on contextual factors impacting the business planning-performance relationship in small firms", Journal of Business Venturing, Vol. 25 No. 1, pp. 24-40.

Brinckmann, J., Dew, N., Read, S., Mayer-Haug, K. and Grichnik, D. (2019), "Of those who plan: a metaanalysis of the relationship between human capital and business planning", Long Range Planning, Vol. 52 No. 2, pp. 173-188.

Burke, A., Fraser, S. and Greene, F. (2010), "The multiple effects of business planning on new venture performance", Journal of Management Studies, Vol. 47 No. 3, pp. 391-415.

Burns, B.L., Barney, J.B., Angus, R.W. and Herrick, H.N. (2016), "Enrolling stakeholders under conditions of risk and uncertainty", Strategic Entrepreneurship Journal, Vol. 10 No. 1, pp. 97-106.

Camuffo, A., Cordova, A., Gambardella, A. and Spina, C. (2019), "A scientific approach to entrepreneurial decision making: evidence from a randomized control trial”, Management Science. doi: 10.1287/mnsc.2018.3249.

Chang, S.J., Van Witteloostuijn, A. and Eden, L. (2010), "From the editors: common method variance in international business research", Journal of International Business Studies, Vol. 41 No. 2, pp. 178-184.

Chaston, I. (2008), "Small creative industry firms: a development dilemma?", Management Decision, Vol. 46 No. 6, pp. 819-831.

Chen, T., Simon, M., Kim, J. and Poploskie, B. (2015), "Out of the building, into the fire: an analysis of cognitive biases during entrepreneurial interviews", New England Journal of Entrepreneurship, Vol. 18 No. 1, pp. 59-70.

Contigiani, A. and Levinthal, D. (2019), "Situating the construct of lean startup: adjacent 'Conversations' and possible future directions", Industrial and Corporate Change, Vol. 28 No. 3, pp. 551-564.

Dawes, J. (1999), "The relationship between subjective and objective company performance measures in market orientation research: further empirical evidence", Marketing Bulletin - Department of Marketing Massey University, Vol. 10, pp. 66-75.

De Clercq, D. and Voronov, M. (2009), "Toward a practice perspective of entrepreneurship entrepreneurial legitimacy as habitus”, International Small Business Journal, Vol. 27 No. 4, pp. 395-419.

Dean, J. and Sharfman, M. (1996), "Does decision process matter? A study of strategic decision-making effectiveness", Academy of Management Journal, Vol. 39 No. 2, pp. 368-392. 
Delmar, F. and Shane, S. (2003), "Does business planning facilitate the development of new ventures?", Strategic Management Journal, Vol. 24 No. 12, pp. 1165-1185.

Felin, T., Gambardella, A., Stern, S. and Zenger, T. (2019), "Lean startup and the business model: experimentation revisited", Forthcoming in Long Range Planning (Open Access), available at SSRN: https://ssrn.com/abstract=3427084 (accessed 29 June 2019).

Fisher, R., Maritz, A. and Lobo, A. (2014), "Evaluating entrepreneurs' perception of success: development of a measurement scale", International Journal of Entrepreneurial Behavior and Research, Vol. 20 No. 5, pp. 478-492.

Flatt, C. and Jacobs, R.L. (2019), "Principle assumptions of regression analysis: testing, techniques, and statistical reporting of imperfect data sets", Advances in Developing Human Resources, Vol. 21 No. 4, pp. 484-502.

Forbes, D.P. (2007), "Reconsidering the strategic implications of decision comprehensiveness", Academy of Management Review, Vol. 32 No. 2, pp. 361-376.

Frederiksen, D. and Brem, A. (2017), "How do entrepreneurs think they create value? A scientific reflection of Eric Ries' lean startup approach”, International Entrepreneurship and Management Journal, Vol. 13 No. 1, pp. 169-189.

Garson, G.D. (2012), Logistic Regression: Binomial and Multinomial, Statistical Associates Publishers, Asheboro, NC.

Ghezzi, A. (2019), "Digital Startups and the adoption and implementation of Lean Startup approaches: effectuation, bricolage and opportunity creation in practice", Technological Forecasting and Social Change, Vol. 146, pp. 945-960, doi: 10.1016/j.techfore.2018.09.017.

Ghezzi, A., Cavallaro, A., Rangone, A. and Balocco, R. (2015), "On business models, resources and exogenous (dis) continuous innovation: evidences from the mobile applications industry", International Journal of Technology Management, Vol. 68 Nos 1-2, pp. 21-48.

Greene, F. and Hopp, C. (2017), "Are formal planners more likely to achieve new venture viability? A counterfactual model and analysis", Strategic Entrepreneurship Journal, Vol. 11 No. 1, pp. 36-60.

Gruber, M. (2007), "Uncovering the value of planning in new venture creation: a process and contingency perspective”, Journal of Business Venturing, Vol. 22 No. 6, pp. 782-807.

Hechavarría, D.M. and Welter, C. (2015), "Opportunity types, social entrepreneurship and innovation: evidence from the panel study of entrepreneurial dynamics", The International Journal of Entrepreneurship and Innovation, Vol. 16 No. 4, pp. 237-251.

Honig, B. (2004), "Entrepreneurship education: toward a model of contingency-based business planning", The Academy of Management Learning and Education, Vol. 3 No. 3, pp. 258-273.

Honig, B. and Karlsson, T. (2004), "Institutional forces and the written business plan", Journal of Management, Vol. 30 No. 1, pp. 29-48.

Honig, B. and Samuelsson, M. (2012), "Planning and the entrepreneur: a longitudinal examination of nascent entrepreneurs in Sweden", Journal of Small Business Management, Vol. 50 No. 3, pp. 365-388.

Honig, B. and Samuelsson, M. (2014), "Data replication and extension: a study of business planning and venture-level performance", Journal of Business Venturing Insights, Vols 1-2 Nos 1-2, pp. 18-25.

Jacobs, S., Cambre, B., Huysentruyt, M. and Schramme, A. (2016), "Multiple pathways to success in small creative businesses: the case of Belgian furniture designers", Journal of Business Research, Vol. 69 No. 11, pp. 5461-5466.

Jennings, P. and Beaver, G. (1997), "The performance and competitive advantage of small firms: a management perspective”, International Small Business Journal, Vol. 15 No. 2, pp. 63-75.

Johannisson, B. (2011), "Towards a practice theory of entrepreneuring", Small Business Economics, Vol. 36 No. 2, pp. 135-150.

Karlsson, T. and Honig, B. (2007), "Norms surrounding business plans and their effect on entrepreneurial behavior", Frontier of Entrepreneurship Research, Vol. 27 No. 22, pp. 1-22. 
NEJE

24,1
Karlsson, T. and Honig, B. (2009), "Judging a business by its cover: an institutional perspective on new ventures and the business plan”, Journal of Business Venturing, Vol. 24 No. 1, pp. 27-45.

Katz, J.A., Hanke, R., Maidment, F., Weaver, K.M. and Alpi, S. (2016), "Proposal for two model undergraduate curricula in entrepreneurship", International Entrepreneurship and Management Journal, Vol. 12 No. 2, pp. 487-506.

Keating, A., Geiger, S. and McLoughlin, D. (2014), "Riding the practice waves: social resourcing practices during new venture development", Entrepreneurship: Theory and Practice, Vol. 38, pp. 1207-1235.

Keith, N., Unger, J.M., Rauch, A. and Frese, M. (2016), "Informal learning and entrepreneurial success: a longitudinal study of deliberate practice among small business owners", Applied Psychology, Vol. 65 No. 3, pp. 515-540.

Ladd, T. (2016), "The limits of the lean startup method", Harvard Business Review, Vol. 94 No. 3, pp. 2-3.

Mason, C., Twomey, J., Wright, D. and Whitman, L. (2018), "Predicting engineering student attrition risk using a probabilistic neural network and comparing results with a backpropagation neural network and logistic regression", Research in Higher Education, Vol. 59 No. 3, pp. $382-400$.

Mintzberg, H. (1994), “The fall and rise of strategic planning”, Harvard Business Review, Vol. 72 No. 1, pp. 107-114.

Mintzberg, H. and Waters, J.A. (1985), "Of strategies, deliberate and emergent”, Strategic Management Journal, Vol. 6 No. 3, pp. 257-272.

Osborne, J.W. and Waters, E. (2002), "Four assumptions of multiple regression that researchers should always test", Practical Assessment, Research, and Evaluation, Vol. 8 No. 1, pp. 1-5, 2, doi: 10. 7275/r222-hv23.

Priem, R.L., Rasheed, A.M.A. and Kotulic, A.G. (1995), "Rationality in strategic decision processes, environmental dynamism and firm performance", Journal of Management, Vol. 21 No. 5, pp. 913-929.

Reymen, I.M.M.J., Andries, P., Berends, H., Mauer, R., Stephan, U. and Burg, E. (2015), "Understanding dynamics of strategic decision making in venture creation: a process study of effectuation and causation”, Strategic Entrepreneurship Journal, Vol. 9 No. 4, pp. 351-379.

Richbell, S.M., Watts, H.D. and Wardle, P. (2006), "Owner-managers and business planning in the small firm”, International Small Business Journal, Vol. 24 No. 5, pp. 496-514.

Ries, E. (2011), The Lean Startup: How Today's Entrepreneurs Use Continuous Innovation to Create Radically Successful Businesses, Crown Business, New York: New York.

Sarasvathy, S.D. (2001), "Causation and effectuation: toward a theoretical shift from economic inevitability to entrepreneurial contingency", The Academy of Management Review, Vol. 26 No. 2, pp. 243-263.

Sarasvathy, S.D. and Dew, N. (2008), "Effectuation and over-trust: debating goel and karri", Entrepreneurship: Theory and Practice, Vol. 32 No. 4, pp. 727-737.

Shane, S., Locke, E.A. and Collins, C.J. (2003), "Entrepreneurial motivation", Human Resource Management Review, Vol. 13 No. 2, pp. 257-279.

Shepherd, D. and Gruber, M. (2020), "The lean startup framework: closing the academic-practitioner divide”, Entrepreneurship: Theory and Practice. doi: 10.1177/1042258719899415.

Tabachnick, B.G., Fidell, L.S. and Ullman, J.B. (2007), Using Multivariate Statistics, Pearson, Boston, MA, Vol. 5, pp. 481-498.

Trimi, S. and Berbegal-Mirabent, J. (2012), "Business model innovation in entrepreneurship", International Entrepreneurship and Management Journal, Vol. 8 No. 4, pp. 449-465.

Van Dyne, L. and LePine, J.A. (1998), "Helping and voice extra-role behaviors: evidence of construct and predictive validity", Academy of Management Journal, Vol. 41 No. 1, pp. 108-119. 
Walker, E. and Brown, A. (2004), "What success factors are important to small business owners?", International Small Business Journal, Vol. 22 No. 6, pp. 577-594.

Welter, C. and Kim, S. (2018), "Effectuation under risk and uncertainty: a simulation model”, Journal of Business Venturing, Vol. 33 No. 1, pp. 100-116.

Welter, C., Mauer, R. and Wuebker, R.J. (2016), "Bridging behavioral models and theoretical concepts: effectuation and bricolage in the opportunity creation framework", Strategic Entrepreneurship Journal, Vol. 10 No. 1, pp. 5-20.

Wood, M.S. and McKinley, W. (2010), "The production of entrepreneurial opportunity: a constructivist perspective", Strategic Entrepreneurship Journal, Vol. 4 No. 1, pp. 66-84.

Wood, M.S., Palich, L.E. and Browder, R.E. (2018), "Full steam ahead or abandon ship? An empirical investigation of complete pivot decisions", Journal of Small Business Management, Vol. 17 No. 4, pp. 351-24.

Yang, X., Sun, S.L. and Zhao, X. (2018), "Search and execution: examining the entrepreneurial cognitions behind the lean startup model”, Small Business Economics, pp. 1-13.

York, J. and Danes, J. (2014), "Customer development, innovation, and decision-making biases in the lean startup", Journal of Small Business Strategy, Vol. 24 No. 2, pp. 21-39.

\section{Appendix}

\section{Qualtrics Survey}

[Business Background]

Did you purchase your business or did you start it yourself?

(1) Purchase

(2) Started (or am starting it) myself

When you first started pursuing the business, how many people were on the founding team (including yourself)?

When you first started pursuing the business, how would you have characterized it?

(1) High Tech Startup (External/Venture funded)

(2) Steady Growth Business (Internally/Self-funded)

(3) Lifestyle Business

(4) Other

Which came first for you, the business idea or your decision to start a business - or did they occur together?

(1) Business Idea

(2) Decision to Start a Business

(3) Occurred Together

When did you first take action to pursue this business (eg. open a bank account, register with government, start talking to potential customers, etc.)?

(1) Month (1-12)

(2) Year (YYYY)

Have you received outside financing?

(1) Yes

(2) No 
NEJE

24,1

40
When did you receive outside financing?

(1) Month (1-12)

(2) Year (YYYY)

Have you made a sale?

(1) Yes

(2) No

When did you make your first sale?

(1) Month (1-12)

(2) Year (YYYY)

Have you made enough money to recover your startup expenses?

(1) Yes

(2) No

When did you make enough money to recover your startup expenses?

(1) Month (1-12)

(2) Year (YYYY)

Have you hired any employees?

(1) Yes

(2) No

When did you hire your first employee?

(1) Month (1-12)

(2) Year (YYYY)

[Lean Start Up, Business Planning Practices]

Which of the following did you do prior to starting (or in the beginning phases) of your company?

(1) Interviewed potential customers

(2) Created a prototype

(3) Showed a prototype to potential customers for feedback

(4) Conducted an experiment to better understand some portion of your business

(5) Wrote a business plan

(6) Accepted money for pre-orders

(7) Used customer feedback to alter the direction of your business ("pivoted")

(8) Gathered secondary data on industry statistics or trends

(9) Shared your business plan with people outside the company for feedback

(10) Shared your business plan with people outside the company for funding

How much did each of those activities positively impact the performance of this venture? [Scale is 1 (A Great Deal) to 5 (Not At All)]

(1) Interviewed potential customers

(2) Created a prototype 
(3) Showed a prototype to potential customers for feedback

(4) Conducted an experiment to better understand some portion of your business

Business plans and lean

(5) Wrote a business plan startup

(6) Accepted money for pre-orders

(7) Used customer feedback to alter the direction of your business ("pivoted")

(8) Gathered secondary data on industry statistics or trends

(9) Shared your business plan with people outside the company for feedback

(10) Shared your business plan with people outside the company for funding

\section{[Demographics]}

How old are you? 0.5

What is your sex?
(1) Male
(2) Female
(3) Prefer not to answer

Are you Hispanic or Latino?
(1) Yes
(2) No
(3) Prefer not to answer

What is your race/ethnicity?

(1) White

(2) Black or African American

(3) American Indian or Alaska Native

(4) Asian

(5) Native Hawaiian or Pacific Islander

(6) Other

(7) Prefer not to answer

What is your current marital status?
(1) Married
(2) Living with a partner
(3) Widowed
(4) Divorced
(5) Separated
(6) Never married
(7) Prefer not to answer

What is your highest level of education completed?
(1) Up to 8th grade
(2) Some High School 
NEJE

(3) High School Diploma

(4) Some College

(5) Associate's Degree

(6) Bachelor's Degree

(7) Some Graduate School

(8) Master's Degree

(9) Doctorate

Besides the company you referred to in this survey, how many other companies have you started previously?
(1) 0
(2) 1
(3) More than 1

\section{[Success Criteria]}

How strongly do you agree or disagree with the following statement? [Scale is 1 (Strongly Agree) to 5 (Strongly Disagree)]

(1) My business is a success

Is your business still operational?
(1) Yes
(2) No

Has your business grown since inception? (Select all that apply)
(1) Increased Annual Revenue
(2) Increased Annual Customers
(3) Increased Number of Employees
(4) No/Not Yet

Have you sold the business for a profit?
(1) Yes
(2) No

Have you collected a salary or paid yourself from the business? (enough to live on)

(1) Yes

(2) No

Thank you for completing the survey!

\section{Corresponding author}

Chris Welter can be contacted at: chriswelter@gmail.com

For instructions on how to order reprints of this article, please visit our website: www.emeraldgrouppublishing.com/licensing/reprints.htm Or contact us for further details: permissions@emeraldinsight.com 